\title{
EDITORIAL
}

\section{Advanced prostate cancer}

\author{
Marie C. Hupe ${ }^{1} \cdot$ Axel S. Merseburger $^{1}$
}

Published online: 16 February 2021

(c) The Author(s), under exclusive licence to Springer-Verlag GmbH, DE part of Springer Nature 2021

The therapeutic management as well as the study landscape of advanced prostate cancer has evolved significantly within the last years. This topic issue of the World Journal of Urology helps to keep track with the newest innovations and controversies. It focuses on hormone sensitive and castration-resistant prostate cancer as well as on the newly defined stages oligometastatic prostate cancer and non-metastatic castration-resistant prostate cancer.

Holmes et al. [1] point out in their review article the pivotal role of multidisciplinary teams (or tumor boards) in the management of patients with advanced prostate cancer. These multidisciplinary teams should consist of, among others, urologists, radiologists, pathologist, radiation oncologists, oncologists, and nuclear medicine physicians. Multidisciplinary team approaches and discussions help to keep track of every innovation and to tailor the most beneficial therapy for each individual patient.

Androgen deprivation therapy (ADT) is the backbone of the treatment of metastatic prostate cancer. Androgen deprivation can be chemically induced by either gonadotropinreleasing hormone $(\mathrm{GnRH})$ agonists or antagonists. There are still controversies whether GnRH agonists increase the risk for cardiac events. Davey et al. [2] provide more data to resolve this riddle. In their population-based cohort ( $n=9081$ patients included) conducted in the United Kingdom primary care setting the relative risk of cardiac events was significantly lower for patients receiving a $\mathrm{GnRH}$ antagonist as ADT compared to GnRH agonists. Based on their results, the authors advocate identifying patients at risk for cardiac events when choosing ADT medications. These findings are in line with the previous HERO phase III data

Marie C. Hupe

mariechristine.hupe@uskh.de

Axel S. Merseburger

axel.merseburger@uksh.de

1 Department of Urology, University Hospital Schleswig-

Holstein, Campus Lübeck, Ratzeburger Allee 160,

23538 Lübeck, Germany showing a better cardiovascular side effect profile when a GnRH antagonist was given [3].

As more and more targeted and minimally invasive treatment options evolve in the therapy management of prostate cancer, the oligometastatic setting gains more interest. Designing trials for this setting including local treatment options or metastasis-directed treatment options are en vogue. De Bruycker et al. [4] analyze and sum up the current landscape of studies for oligometastatic prostate cancer. Also Walz et al. [5] dedicated themselves on the available literature about local treatment options for metastatic prostate cancer patients. However, they focused on local treatment options of the prostate in hormone sensitive metastatic prostate cancer patients including both, surgery and radiation therapy. Following their extensive analysis of the available literature, Walz et al. conclude that local radiotherapy might be beneficial in low volume hormone sensitive metastatic prostate cancer patients.

Not only the oligometastatic, but also the polymetastastic state of prostate cancer steadily experiences innovations, especially the hormone sensitive metastatic prostate cancer. Within the last years, medications usually applied in the castration-resistant setting, such as Docetaxel or Abiraterone, are now being applied in the hormone sensitive setting, too. Additionally, there are new inhibitors of the androgen receptor pathway on the market, such as Apalutamide, Darolutamide, or Enzalutamide. Kwan et al. [6] provide in their review guidance for the jungle of systemic treatment for hormone sensitive metastatic prostate cancer patients.

Within this edition of advanced prostate cancer, we move on to a new kid on the block indication: the non-metastatic castration-resistant prostate cancer, i.e. disease progression to castrations resistance without detectable metastases on conventional bone scan or computer tomography. HessBusch et al. [7] illustrate the current treatment options as well as discuss the pivotal phase III trials for this newly defined stage of the disease.

Last but not least, this topic issue draws the attention to the physical fitness of castration-resistant prostate cancer patients. Bultijnck et al. [8] performed a trial with nine 
patients undergoing different training programs. Results of this study can be of help when designing training programs for metastatic castration-resistant prostate cancer patients.

This topic issue of the World Journal of Urology on advanced prostate cancer includes key innovations within the treatment of metastatic prostate cancer and controversies being discussed among top notch uro-oncologists all over the world.

We invite you to read this special edition to open up new innovations and controversies.

\section{References}

1. Holmes A, Kelly BD, Perera M et al (2020) A systematic scoping review of multidisciplinary cancer team and decision-making in the management of men with advanced prostate cancer. World J Urol. https://doi.org/10.1007/s00345-020-03265-1

2. Davey P, Kirby MG (2020) Cardiovascular risk profiles of GnRH agonists and antagonists: real-world analysis from UK general practice. World J Urol. https://doi.org/10.1007/s00345-020-03433 $-3$

3. Shore ND, Saad F, Cookson MS, George DJ, Saltzstein DR, Tutrone R, Akaza H, Bossi A, van Veenhuyzen DF, Selby B,
Fan X, Kang V, Walling J, Tombal B, HERO Study Investigators (2020) Oral relugolix for androgen-deprivation therapy in advanced prostate cancer. N Engl J Med 382(23):2187-2196

4. De Bruycker A, Tran PT, Achtman AH et al (2020) Clinical perspectives from ongoing trials in oligometastatic or oligorecurrent prostate cancer: an analysis of clinical trials registries. World $\mathrm{J}$ Urol. https://doi.org/10.1007/s00345-019-03063-4

5. Walz J, Pignot G, Fakhfakh S et al (2020) Metastatic hormone sensitive prostate cancer: local treatment strategies. World J Urol. https://doi.org/10.1007/s00345-020-03296-8

6. Kwan EM, Thangasamy IA, Teh J et al (2020) Navigating systemic therapy for metastatic castration-naïve prostate cancer. World J Urol. https://doi.org/10.1007/s00345-019-03060-7

7. Hess-Busch Y, Hadaschik B, Hess J (2019) M0CRPC overview of management options. World J Urol. https://doi.org/10.1007/s0034 5-019-02997-z

8. Bultijnck R, Deforche B, Borrey N et al (2020) Exercise prescription dose for castrate-resistant prostate cancer patients: a phase I prescription dose escalation trial. World J Urol. https://doi. org/10.1007/s00345-020-03098-y

Publisher's Note Springer Nature remains neutral with regard to jurisdictional claims in published maps and institutional affiliations. 